\title{
artículos
}

\section{A plebe à luz de intérpretes contemporâneos: Ruda e Kristofory}

The Rabble in the Light of Contemporary Interpreters: Ruda and Kristofory HERNANDEZ VIVIAN EICHENBERGER 
Recibido: 3/3/2021

Aceptado: 7/6/2021

Resumo. O presente texto busca reconstruir as interpretações de Frank Ruda e Tomas Kristofory a respeito do conceito de plebe delineado na Filosofia do direito de Hegel. Ambos os autores propõem interpretações fundamentalmente antípodas cujo contraste contribui decisivamente no esclarecimento do papel da plebe na tessitura do pensamento de Hegel. Após a reconstrução apresenta-se a crítica a ambas e, por fim, esboça-se uma resposta ao mesmo problema.

Palavras-chave: Hegel, Ruda, Kristofory, plebe

Abstract. The present text seeks to reconstruct the interpretations of Frank Ruda and Tomas Kristofory regarding the concept of rabble outlined in Hegel's Philosophy of Right. Both authors propose fundamentally antipode interpretations whose contrast contributes decisively to clarifying the role of the rabble in the structure of Hegel's thought. After the reconstruction, the criticism is presented to both and, finally, an answer to the same problem is outlined.

Keywords: Hegel, Ruda, Kristofory, rabble 
$\mathrm{O}$ problema da plebe em Hegel tem mobilizado boa parte dos intérpretes contemporâneos de sua filosofia política. A questão toda, em especial, é tanto mais nevrálgica quanto mais se ressalta seu lugar estratégico no pensamento de Hegel, seja na economia interna da Filosofia do direito - o momento da transição para o Estado-, seja em virtude do fato de ela própria ser como uma espécie de cifra ou entroncamento de um conjunto mais amplo de questões: pobreza, comércio, colonização. Assim, uma investigação sistemática sobre a plebe talvez permita equacionar a posição de Hegel a respeito do capitalismo, tema ao mesmo tempo antediluviano e atual entre os comentadores. ${ }^{1}$ No presente texto procederemos a uma breve reconstrução do texto de Hegel que menciona explicitamente a plebe, seguido de uma sumária apresentação dos comentadores clássicos. Depois exploraremos, de maneira detida, a posição de comentadores contemporâneos. Por fim, esboçaremos uma resposta própria aos problemas interpretativos levantados.

Sabe-se que os $§ \S$ 243-248 da Filosofia do direito de Hegel condensam o tema da plebe, embora não o esgotem: há muito material disperso ao longo de toda obra (no Sistema da eticidade, na assim chamada Filosofia real, na Filosofia da história, no artigo sobre o Reformbill, etc.). Ainda assim, é na Filosofia do direito em que esse tema é apresentado da maneira mais estruturada. Desse modo, apresentaremos sucintamente uma reconstrução geral a partir dessa obra.

No $§ 243$ Hegel aponta que a sociedade civil-burguesa, quando funciona em sua «eficácia desimpedida» ${ }^{2}$-isto é, sem freios ou contrapesos--, experimenta um aumento crescente de povoação e de industrialização. A própria dinâmica do trabalho em seu processo de universalização, na medida que visa a satisfação de carecimentos, acaba por operar o entrelaçamento entre os homens e seus modos de preparar e distribuir os produtos, e assim conduz à acumulação de riquezas, por um lado, e à miséria da classe que vive do trabalho,

1 LUKÁCS, G., O Jovem Hegel e os problemas da sociedade capitalista, Boitempo, São Paulo, 2018; BUCHWALTER, A. (Ed.), Hegel and Capitalism, Suny Press, New York, 2015.

2 HEGEL, G. W. F., Filosofia do direito, Loyola/UNISINOS, São Paulo/São Leopoldo, 2010, § 243. 
por outro. Ou seja, Hegel inscreve na estrutura mesma da sociedade civil-burguesa o modo pelo qual ela produz acumulação e pobreza. O que Hegel está descrevendo é fundamentalmente a estrutura das sociedades de mercado modernas. Quando um conjunto de indivíduos decai na pobreza, até o ponto de perder os laços mais básicos de integração social ( $\$ 244)$, ocorre a formação da plebe. A plebe, contudo, não é um resultado automático da pobreza: «A pobreza em si não torna ninguém parte da plebe: esta só é determinada como tal pelo estado de ânimo que se combina com a pobreza, pela revolta interna contra os ricos, contra a sociedade, contra o governo, etc.». ${ }^{3}$ Essa configuração psicossocial conduz a plebe a reivindicar a sua subsistência, contudo não através da mediação pelo trabalho. Embora Hegel não subscreva essa pretensão, ainda assim ele a reconhece. Trata-se de uma demanda dirigida à sociedade de um problema produzido por ela, daí que haja alguma legitimidade nela:

Face à natureza, nenhum homem pode afirmar um direito, mas no estado de sociedade o fazer falta adquire, em seguida, a forma de uma injustiça feita a esta ou àquela classe. A pergunta importante, sobre como remediar a pobreza, é uma pergunta que prioritariamente move e atormenta as sociedades modernas. ${ }^{4}$

Ora, Hegel passa então às soluções possíveis para impedir a formação da plebe. A primeira possibilidade seria a manutenção do conjunto de pessoas que a formam através da ajuda direta dos ricos (por meio de instituições específicas) ou através de impostos progressivos. Essa solução é recusada em virtude do fato de ela prescindir do princípio do trabalho e, portanto, violar a autonomia e dignidade daqueles que permaneceriam em um estado permanente de socorro social. Outra possibilidade aventada -e, embora criticada, veremos que será adotada- é a mediação pelo trabalho. O problema dessa alternativa, por sua vez, consiste em que ela acaba por produzir um novo problema, isto é, a produção de uma quantidade tamanha de produtos que a eles faltam consumidores. $\mathrm{O} \oint 245$ conclui pessimista e mesmo aporético:

Aqui aparece que a sociedade civil-burguesa, apesar do seu excesso de riqueza, não é suficientemente rica, isto é, não possui, em seu patrimônio próprio, o suficiente para governar o excesso de miséria e a produção da populaça. ${ }^{5}$

No comentário ao $§ 245$, Hegel explicita a dimensão histórica do problema, de como ele se encontra em sua forma mais patente e extremada na Inglaterra

3 HEGEL, G. W. F., A sociedade civil-burguesa, IFCH/UNICAMP, Campinas, 1996, § 244, p. 75.

4 Ibid., §244, p. 75.

5 HEGEL, G. W. F., Filosofia do direito, op. cit, § 245, p. 223. 
e menciona, ainda, a solução escocesa de «abandonar os pobres a seu destino e os entregar à mendicidade pública». ${ }^{6}$ De qualquer modo, no $§ 246$ são descrito que esse complexo nó social que é a pobreza e a plebe conduz a sociedade civil-burguesa a encontrar consumidores nos produtos que tem em demasia em outros povos - o que leva a se pensar que, por fim, a solução do oferecimento de trabalho foi realmente adotada. Portanto, trata-se aqui de pensar que a exportação poderia ser um meio de atenuamento das tensões sociais tal como inicialmente descritas no $§ 243$.

O $\S 247$ expõe a questão dos mares e, mais importante, o $§ 248$ tematiza a solução da colonização. As dinâmicas conflituosas inscritas na sociedade civil-burguesa orientam à retomada do princípio familiar em um novo solo por meio da colonização. As pessoas que não podem mais encontrar a sua realização através do trabalho em uma dada sociedade se veem compelidas à formação de novas sociedades. Embora alguns autores pensem que se trata aqui de uma solução de caráter tipicamente colonialista, ${ }^{7}$ não parece ser o caso. O próprio Hegel expressamente declarou que «a libertação das colônias revela-se ela própria como a maior vantagem para o Estado da mãe pátria, assim como a libertação dos escravos para o senhor». ${ }^{8}$

Realizada essa reconstrução sumária, ${ }^{9}$ passemos ao problema: os remédios elencados nesses parágrafos -que basicamente concluem as menções explícitas de Hegel em relação à plebe-- são o suficiente para supormos que a questão foi bem resolvida? O encaminhamento da questão delineado por Hegel foi realmente persuasivo? As soluções aventadas são capazes de mitigar, dirimir e mesmo superar o caráter refratário da plebe? Não é possível pensar, que o problema de fundo - a dinâmica disruptiva da sociedade

6 Esse é um ponto frequentemente mal compreendido. Contudo, ele pode ser dirimido através da observação histórica de Norbert Waszek, que demonstra como, a partir de algumas regulamentações específicas, a Escócia garantiu um estatuto bastante sui generis à mendicância: «que o mendigo escocês licenciado não pudesse ser confundido com pessoas que extorquiam a caridade de seus semelhantes, dava a ele uma vantagem material. Comparado com seus colegas ingleses ou europeus, ele se mostrava como um mendigo "upper-class". A recomendação de Hegel do "método escocês" pode, assim, ser interpretada não como aspereza insensível contra os pobres». WASZEK, N., "O mendigo escocês de Hegel», Revista Eletrônica Estudos Hegelianos 15(26), 2018, 235-241, p. 237.

7 David Harvey e Ruben Dri entendem, ambos, a posição de Hegel como tipicamente colonialista. Além dessa ideia estar em desacordo com o adendo ao § 248, ela é incompatível com o sentido geral da filosofia de Hegel - uma filosofia da liberdade. A esse respeito, ver HARVEY, D., «O Ajuste Espacial: Hegel, Von Thünen e Marx», en: A Produção capitalista do espaço, Annablume, São Paulo, 2005, p. 101; DRI, R. «A filosofia do Estado ético. A concepção hegeliana do Estado», en: BORON, A. (Ed.), Filosofia política moderna. De Hobbes a Marx. CLACSO, San Pablo, 2006, p. 234.

8 HEGEL, G. W. F., A sociedade civil-burguesa, op. cit., § 248, p. 79

9 Uma leitura pormenorizada do argumento de Hegel foi procedida no capítulo 1 de EICHENBERGER, H. V., Pobreza e Plebe em Hegel. 2018. P. 195. Tese (Doutorado em Filosofia), Universidade Federal do Paraná, Curitiba, 2018. 
civil-burguesa- não foi de fato encarado, na medida em que mesmo em novas terras colonizadas ele simplesmente irá se repor, o que exigirá, mais uma vez, o reinício do processo? A essa questão se voltaram importantes comentadores de Hegel.

No geral, comentadores clássicos do problema se devotaram a perguntas semelhantes. Apenas para citar alguns desses intérpretes, os comentários de Rosenzweig, Eric Weil, Adorno e Avineri dedicaram sua atenção à pobreza e aos temas correlatos a ela, sobretudo enfatizando a Filosofia do direito e privilegiando os parágrafos comentados acima. A recapitulação sumária de suas interpretações ilumina os problemas que podem ter sido deixados em aberto por Hegel.

Conforme o comentário de Franz Rosenzweig, a tematização da plebe fez Hegel colocar questões sociais de maneira premonitória. O § 244 da Filosofia do direito é responsável por marcar a «conexão conceitual entre teoria da pauperização, exército industrial de reserva e lei de bronze dos salários». ${ }^{10}$ Para Rosenzweig, Hegel está defronte da questão do proletariado: «a palavra proletariado ainda não era usada». ${ }^{11}$ Para ele, a criação da plebe é uma tendência férrea da sociedade, um de seus «defeitos inevitáveis», ${ }^{12}$ explicada em virtude de que a conjugação do isolamento e limitação do trabalho somados a carecimentos infinitos dariam início a um «processo [que] segue sempre adiante por si mesmo». ${ }^{13}$ Em que pese o pioneirismo de Rosenzweig, ou seja, a colocação do problema, é difícil não julgar suas observações como eivadas de um comprometedor anacronismo. A identificação entre plebe e proletariado acaba por não ser bem justificada e observações segundo as quais Hegel teria introduzido a questão da plebe «totalmente no espírito do futuro socialismo científico» ${ }^{14}$ traem a falta de consonância com os termos nos quais o próprio Hegel compreendeu a questão.

Segundo Eric Weil, por outro lado, a plebe permite redimensionar de maneira decisiva o modo pelo qual o sistema de Hegel deve ser visto. A plebe é tão mais significativa na medida em que denota uma abertura do sistema de Hegel, algo cujas leituras mais vulgares insistem em recusar: «há homens no Estado que negam o Estado, que trabalham, pois, para sua destruição. Como explicar esse fato?». ${ }^{15}$ A plebe é essa falta constitutiva que acentua a incompletude do sistema e, por isso mesmo, demanda novas soluções que seriam apenas esboçadas por Hegel.

10 ROSENZWEIG, F., Hegel und der Staat, Oldenbourg, München/Berlin, 1920, Bd. II, p. 125. Citarei preferencialmente a edição brasileira, mas nesse trecho a formulação está bastante imprecisa.

11 ROSENZWEIG, F., Hegel e o Estado, Perspectiva, São Paulo, Perspectiva, 2008, p. 458.

12 Ibid., p. 459.

13 Ibid., p. 457.

14 Ibid., p. 457.

15 WEIL, E., Hegel e o Estado, É Realizações, São Paulo, 2011, p. 104. 
Para Adorno, o § 243 da Filosofia do Direito é aquele que apresenta «o mais antigo modelo sociológico de uma contradição que necessariamente se desenvolve no objeto». ${ }^{16}$ Portanto, trata-se de uma contradição cuja resolução não passa por um acréscimo de conhecimento que a desvaneceria como um mero engano do sujeito. Ao contrário, é ela própria distintiva da estrutura mesma do objeto, a saber, nesse caso, da sociedade civil-burguesa. Em outros termos, «a sociedade civil é uma totalidade antagônica. Ela sobrevive apenas em e por meio de seus antagonismos, não sendo capaz de resolvê-los. Isso é formulado sem floreios na Filosofia do direito». ${ }^{17}$ As dinâmicas sociais que produzem a pobreza convocam o Estado como o mecanismo para assegurar a não dissolução da sociedade enquanto tal: «o Estado é solicitado desesperadamente como uma instância para além desse jogo de forças». ${ }^{18}$ Isso, porém, não ocorre de maneira imanente, ou seja, não através do encadeamento necessário das categorias que expõem ou apresentam a reconstrução lógica do Espírito Objetivo. Ao contrário, o Estado comparece nesse ponto como um ato de violência. É como se Hegel tivesse traído a dialética em favor do sistema; infidelidade necessária e reveladora da profunda verdade do pensamento hegeliano, ainda que ele próprio não fosse capaz de levar seu pensamento às suas próprias e últimas consequências.

Shlomo Avineri, em seu Hegel's Theory of the Modern State, amplia a compreensão do problema da pobreza de maneira rigorosa. Segundo ele, «não é o mau funcionamento da sociedade civil que causa a pobreza, mas precisamente seu oposto, o regular funcionamento dos poderes do mercado». ${ }^{19} \mathrm{~A}$ reconstrução de Avineri joga luz na impropriedade de se identificar a plebe ao proletariado: «uma multidão de seres humanos completamente atomizados e alienados da sociedade, sem sentimento de fidelidade a ela e já nem sequer desejando ser integrados a ela». ${ }^{20} \mathrm{Ou}$ seja, a plebe carece de um caráter construtivo, sua negatividade não encarna nenhuma positividade, ainda que potencial. Ao se voltar às soluções da pobreza que Hegel encaminha, Avineri, de maneira aturdida, afirma: «essa é a única vez em seu sistema em que Hegel levanta um problema - e deixa-o aberto». ${ }^{21}$

Essas não são, evidentemente, as últimas palavras sobre o assunto. O debate permanece contemporaneamente motivando intervenções. Pinçaremos duas

16 ADORNO, T. W., Sociologia, Ática, São Paulo, 1994, p. 49.

17 ADORNO, T. W., Três estudos sobre Hegel, UNESP, São Paulo, 2013, p. 104.

18 Ibid., p. 105.

19 AVINERI, S., Hegel's theory of the modern state, Cambridge, New York, 1972, p. 149.

20 Ibid., p. 150.

21 Ibid., p. 154. Uma tentativa de reconstrução mais sistemática desses comentários pode ser encontrada em EICHENBERGER, H. V., «A plebe segundo os intérpretes de Hegel», en: CORREIA, A. DEBONA, V. y TASSINARI, R. (Eds.) Hegel e Schopenhauer. São Paulo: ANPOF, 2017, pp. 143-158. 
contribuições que são tão instigantes quanto divergentes: a posição consubstanciada no livro Hegel's Rabble, de Frank Ruda, e o texto Hegel's Emigrating Rabble and Export of Institutions of Civil Society, de Tomas Kristofory. O objetivo aqui é reconstruir sucintamente a tese de cada um deles e pô-las em diálogo. Ao final sugeriremos que as respostas de ambos, ainda que bastante estimulantes, não são suficientes para fornecer uma solução satisfatória aos dilemas interpretativos.

Frank Ruda, em seu livro Hegel's Rabble, busca desenvolver uma grande tese em torno do conceito de plebe em Hegel. Sua ideia básica é que da plebe é possível pensar a passagem de Hegel a Marx, a saber, da plebe ao proletariado. Segundo Ruda, «o pressuposto do presente livro é que a transformação da filosofia introduzida por Marx começa a partir da plebe». ${ }^{22}$ Para cumprir esse propósito, Ruda precisa prestar contas com os comentadores mais clássicos de Hegel. Ele trata de contestar - a nosso ver, com precisão e razão- o ponto de vista de Avineri segundo o qual o conjunto de questões que envolve a pobreza/ plebe não teria sido realmente tocada por Hegel, isto é, que este não teria oferecido um tratamento a elas. Ruda é enfático em dizer que, ao contrário do que supõe Avineri, Hegel ofereceu sete tipos de tratamento à questão da pobreza:

As sete soluções são: 1. o tratamento dos pobres pela sociedade civil ela mesma; 2. mendicância pública; 3. o direito da penúria [das Notrecht]; 4. colonização; 5. redistribuição do trabalho; 6. a corporação e sua ética (de consumo responsável); 7. a polícia e, em combinação com isso, a religião (na forma de instituições caritativas). ${ }^{23}$

Todas as alternativas aduzidas falham por um ou outro motivo. Nisso não está propriamente a novidade de Ruda, mas sim no fato de ter sido, até onde nos consta, o primeiro a considerar a problemática da plebe rica em toda sua extensão. Ora, que haja uma dinâmica estrutural que condicione o surgimento da plebe e que ela própria implique em uma disposição de espírito é algo bastante assentado no texto da Filosofia do direito. Contudo, não há uma menção explícita de uma plebe rica no texto publicado. Há, bem entendido, uma menção implícita, uma sugestão, em que pese o termo não estar presente. ${ }^{24} \mathrm{Nas}$ lições de 1821-22 Hegel menciona esse outro tipo de plebe:

Há também a plebe rica. Pois a riqueza é um poder, e esse poder da riqueza facilmente descobre que é o poder sobre o direito [...] Essa disposição

22 RUDA, F., Hegel's Rabble. A investigation into Hegel's Philosophy of Right, Continuum, London, 2011, p. 5.

23 Ibid., p. 15; RUDA, F., Hegels Pöbel. Eine Untersuchung der Grundlinien der Philosophie des Rechts, Konstanz University Press, Konstanz, 2011, p. 37.

24 HEGEL, G. W. F., Filosofia do direito, op. cit, § 253, p. 227; HEGEL, G. W. F., Grundlinien der Philosophie des Rechts, Suhrkamp, Frankfurt am Main, 1986, p. 395. 
assinala que a riqueza é poder contra o direito, é contra o ético [Sitte], enquanto esse existe; então a riqueza toma, do mesmo modo, em si e para si um estado de perda de direito [Rechtlosigkeit], no qual ela é um poder ${ }^{25}$.

É evidente que o que importa nessa definição de plebe é a dimensão da «disposição moral» torpe conferida pela riqueza elevada e que se choca contra os interesses éticos da sociedade. ${ }^{26}$ A plebe rica é, igualmente à pobre, carente de direitos no que toca a seu reconhecimento: nela há uma confusão entre dinheiro e poder, uma imposição da riqueza sobre os costumes, de modo que ela própria se autocompreende para além do direito. Segundo Ruda, «a plebe rica coloca seu comando soberano de poder puramente econômico contra a soberania do Estado e suas instituições». ${ }^{27}$ Ela tem sua existência ligada à riqueza que se desliga de algum nível de eticidade mais estável: «qualquer riqueza fora da corporação e dos estamentos é propriedade da plebe rica». ${ }^{28} \mathrm{~A}$ semelhança entre ambas é que permanecem, do ponto de vista do horizonte de suas aspirações, no estágio da sociedade civil, enquanto pessoas privadas.

A despeito das semelhanças existentes, Ruda enfatiza a distinção entre elas. Em um caso, se escolhe não pertencer à corporação e às esferas éticas mais elevadas e, assim, adentrar ao contingente jogo de perdas e ganhos da economia de mercado; no outro caso, a «decisão» (ou, melhor, a disposição que a plebe encarna) se efetiva frente a uma dura objetividade posta: «de um lado, nós temos uma operação subjetiva gerando as condições de possibilidade, de outro lado nós temos uma operação subjetiva que já depende de uma inevitável condição objetiva de possibilidade da mesma operação». ${ }^{29}$ Outra diferença reside no sentimento básico que orienta as duas plebes. Enquanto a rica toma a forma da depravação, a pobre tem como sentimento a indignação -os termos técnicos são Verdorbenheit e Empörung:

Depravação [Verdorbenheit], por um lado, como uma expressão da hipóstase de si mesmo, da particularidade isolada tornada a única forma absoluta de universalidade, e indignação [Empörung], por outro, como a expressão de uma experiência de privação de direitos, são os dois lados de uma moeda cujo nome é "plebe". Depravação e indignação são nomes que para

25 HEGEL, G. W. F., Die Philosophie des Rechts. Vorlesung von 1821/22, Suhrkamp, Frankfurt am Main, 2005, pp. 222-223.

26 Vale lembrar aqui, como provável fonte, as observações de Adam Ferguson a respeito de uma riqueza desligada da virtude (ou seja, luxo com corrupção) e que, por isso mesmo, acaba por dissolver o Estado; FERGUSON, A., «Do Luxo», en: PIMENTA, Pedro Paulo (Ed.), O lluminismo Escocês, Alameda, São Paulo, 2011, pp. 98-99.

27 RUDA, F., Hegel's Rabble, op. cit., p. 38.

28 Ídem.

29 Ibid., p. 50. 
Hegel são os dois lados de uma posição subjetiva e convicção que é dirigida contra a comunidade ética enquanto tal. ${ }^{30}$

Além disso, os vínculos sociais que se desmancharam ou nunca efetivamente se constituíram - os quais, por definição, caracterizam a plebe- ${ }^{-}$são retomados em algum nível pela plebe rica, na medida em que ela desfruta de riqueza e poder, algo que é impossível à plebe pobre. Ambas têm como semelhança não retirarem do trabalho sua subsistência, todavia isso não resulta num mesmo tipo de atitude. Viver sem trabalhar é «a razão pela qual a plebe pobre se torna preguiçosa/repulsiva (faul) e a plebe rica se torna esbanjadora/extravagante (verschwenderisch)». ${ }^{31}$ Ruda formaliza duas lógicas que regem as diferentes plebes. A plebe rica é formalizada segundo C-C-N. Isso porque é contingente a operação subjetiva que direciona o indivíduo a dedicar-se ao enriquecimento, tal como é contingente que ele ganhe no jogo da sociedade civil, ao passo que é necessário que a plebe rica subordine a si própria à arbitrariedade, fazendo demonstrações externas de seu poder econômico, isto é, ostentando. Inicialmente, a plebe pobre pode ser formalizada como N-C: a pobreza é impingida necessariamente a um setor da população, todavia o modo como lidarão com ela, assumindo resignadamente a pobreza ou se indignando frente a ela, é contingente. Ruda marca como distinção entre ambas ainda a manifestação externa delas. A plebe rica em sua extravagância tem como manifestação a luxúria. Já à plebe pobre falta toda manifestação externa: «não há critério exterior que nos permitiria detectar se o pobre é uma plebe pobre ou um pobre diabo». ${ }^{32}$ A sugestiva analogia de Ruda é que a plebe pobre é como o «Branco sobre Branco» de Malevich.

A existência da plebe, por sua vez, tem como condições cisões que lhe antecedem. ${ }^{33}$ Essas divisões assinalam um terceiro elemento que caracteriza a lógica da plebe pobre que não foi ela mesma descrita por Hegel. Ruda se apoia na tese de Adorno segundo a qual Hegel teria recuado frente à negatividade e assumido a positividade do sistema em troca da abertura que encarar a plebe proporcionaria. ${ }^{34}$ Isso conduz Ruda a desenvolver uma teoria do ressentimento na perspectiva de complementar Hegel. Essa teoria está apenas indicada e aqui Ruda segue suas próprias formulações. O sentido desse

30 Ibid., 51 y 86.

31 Ibid., p. 53 y 87.

32 Ibid., p. 57.

33 «Até agora descrevi várias cisões: a sociedade civil divide-se entre aqueles que encontram trabalho e um lugar em estamento e aqueles que são meras pessoas privadas; pessoas privadas divididas em pobres e jogadoras; os pobres se dividiram em pobres e plebe pobre; os jogadores dividiram-se em jogadores e plebe rica; a plebe se divide em plebe rica e plebe pobre», ibid., p. 58.

34 Ibid., p. 59. 
ressentimento consiste em que a plebe positivamente ${ }^{35}$ indigna-se frente ao Estado e à sociedade civil. ${ }^{36}$ Esse viés «positivo» da plebe escapa inteiramente a Hegel. Todavia, essa indignação da plebe resulta em uma contradição. Isso porque ela retira o padrão de sua crítica do próprio direito que ela mesma denuncia como particular. ${ }^{37}$ Esse «direito sem direito», isto é, a reivindicação de que a sociedade deve sustentar a manutenção de sua existência mesmo sem trabalho, é, contudo, uma reivindicação particular, a qual não avança à universalidade. Nisso consiste aquilo que Ruda chama de ressentimento, a saber, a pretensão do estabelecimento de uma norma que valha para si sem valer para os demais. ${ }^{38}$

Por outro lado, a plebe rica não nega o direito como um todo, mas como que permanece em um estágio inferior dele. Ao afirmar sua riqueza, ainda que desligada de pressupostos éticos, ela afirma a categoria da propriedade, de modo que ela «permanece no interior do direito existente». ${ }^{39}$ Por outro lado, a plebe pobre expressa seu ressentimento na alegação de que deve ser sustentada mesmo sem trabalho, o que estrutura aquilo que Ruda chama «direito sem direito». O ponto para o qual a dialética de Hegel se mostra deficitária consiste no fato de que ela não consegue ou pode condenar a sociedade civil como um todo. ${ }^{40}$ Dessa maneira, o que Ruda quer enfatizar consiste justamente em pensar a plebe como uma espécie de chave conceitual que permitiria ler o conjunto da filosofia de Hegel: «o problema é que a plebe pobre mostra que excede a categorização filosófica de Hegel». ${ }^{41}$ Graças à lógica da dupla latência -a saber, qualquer um na sociedade é de modo latente pobre e de modo latente plebe--, Ruda pode encaminhar sua argumentação no sentido de que as alegações que a plebe pobre sustenta podem recair em uma espécie de novo direito que se diferencia substantivamente daquilo que a plebe rica é capaz de sustentar. Segundo Ruda,

35 «Ele [Hegel], ou pelo menos eu pretendo sustentar, suspende o terceiro elemento da lógica da emergência da plebe pobre porque ele a interpreta apenas como um "entendimento negativo"», ídem.

36 «A plebe, indignada e insatisfeita, acusa a sociedade, o governo etc. e declara que o estado da sociedade civil e a ordem do Estado são um estado sem direito», ibid., p. 60.

37 «Porque, de um lado, sua falta não é reconhecida como uma injustiça pelo direito existente e, por outro, ele mesmo julga ser um insulto ao direito, uma injustiça; ele, ao mesmo tempo, julga que o Estado de direito dado não é um Estado de Direito. Como o direito não apoia seu julgamento sobre a injustiça, ele experimenta a perda para ele de estar em seu direito, isto é, a legalidade como tal. Essa é a razão de sua indignação», ibid., p. 61.

38 «Sustentar um direito que fundamentalmente não complete as condições de possibilidade de ser um direito -por ser meramente particular- por ser um direito sem direito é a estrutura básica daquilo que se pode chamar de ressentimento em Hegel», ídem.

39 Ibid., p. 62.

40 «A consequência decisiva dessa ideia (insight) é que a própria sociedade civil produz constantemente injustiças. Mas Hegel não pode tirar essa consequência, uma vez que a sociedade civil é parte da organização racional do ético», ibid., p. 63.

41 Ibid., p. 64. 
A plebe pobre declara assim um direito sem direito que é válido somente para ela, mas (latentemente) para qualquer um. Ou colocando isso de modo distinto: a plebe pobre dirige um direito como seu direito que é meramente particular e, contudo, ao mesmo tempo, latentemente universal. $\mathrm{O}$ direito sem direito da plebe rica é meramente particular. ${ }^{42}$

Haveria mais vários detalhes e liames argumentativos a se evidenciar, porém para uma apresentação sinótica é suficiente anotar que para Ruda a plebe pobre instaura uma dimensão que o próprio Hegel, ainda que tenha antevisto, não pôde compreender em toda a sua extensão. Essa dimensão, por sua vez, não é puramente negativa, no sentido de que não se trata de um setor da população renitentemente negando-se a se integrar socialmente, mas sim ele próprio - o que Hegel não poderia reconhecer- inaugura a possibilidade de pensar um direito da igualdade fundado na ideia de indignação. ${ }^{43}$ Nas palavras de Žižek, que em seu livro Menos que nada se apoia inteiramente em Ruda nesse aspecto,

A questão, obviamente, é que aqui também podemos aplicar a diretriz dialética fundamental: esses fracassos locais na tentativa de desenvolver de maneira apropriada o mecanismo do processo dialético são seus pontos sintomáticos imanentes, eles indicam uma falha estrutural mais fundamental no próprio mecanismo de base. Em suma, se Hegel tivesse sistematizado o caráter universal da populaça, seu modelo inteiro do Estado racional teria de ser abandonado. ${ }^{44}$

No polo oposto dessa interpretação sem dúvida está Tomás Kristofory. ${ }^{45}$ Sua tese principal é que sobre o problema levantado até agora não há basicamente nenhum problema de fato. A questão suscitada sobre colonização, pobreza, exportação etc., não implica em nenhuma anomia a qual Hegel estaria detectando e comprometendo seu sistema. Segundo Kristofory, «à diferença de interpretações alternativas, descobrimos que Hegel não ofereceu a migração como um meio de aliviar a pobreza, mas como um meio de exportar instituições de estrutura moral

42 Ibid., p. 65.

43 RUDA, F., «A populaça ou: o fim do Estado hegeliano», Revista Eletrônica Estudos Hegelianos 16 (28), 2019, 1-21, pp. 14-15.

44 ZIZEK, S., Menos que nada: Hegel e a sombra do materialismo dialético, Boitempo, São Paulo, 2013, p. 289.

45 KRISTOFORY, T., Hegel's Emigrating Rabble and Export of Institutions of Civil Society, October 2015. Disponível em: https://pt.scribd.com/document/306659733/Hegels-Par-243-248-GPR; Acesso em 28/01/2018. No mesmo sentido, merece ser citado o artigo de LEUVEN, S., «The Problem of Poverty and the Rabble: Against the Neo-Marxist Critique of Hegel», en: ARNDT, A. et al. (Hrsg.), Hegel Jahrbuch-2014: Hegel gegen Hegel I, Walter de Gruyter, Berlin/München/ Boston, 2014. 
da sociedade civil para o país colonizado» ${ }^{46} \mathrm{Ou}$ seja, a colonização não teria como função precípua mitigar os problemas derivados das contradições internas das sociedades, mas sim um fim ético, a saber, espalhar as instituições do país colonizador sobre o globo, notadamente instituições ligadas ao comércio. Segundo Kristofory, não há qualquer círculo vicioso envolvido no argumento:

Tanto o país colonizador quanto o colonizado crescem mais ricos. Apesar de o país colonizador inicialmente querer explorar o país colonizado, mais tarde os colonizadores percebem, será melhor se os libertarem. O efeito final para o país colonizador será o crescimento de sua produtividade e população. Aqui o círculo do argumento chega ao fim. A plebe é superada [sublated], produtividade e população crescem. ${ }^{47}$

Uma parte importante do argumento de Kristofory consiste no deslocamento da questão. Segundo ele, o problema da plebe deve ser visto antes de tudo em termos filosóficos, e não econômicos. Partindo das elaborações de Birger Priddat em seu Hegel als Ökonom, Kristofory afirma que Hegel, ao contrário da célebre formulação de Marx, não se encontra no interior do ponto de vista da moderna economia política. ${ }^{48} \mathrm{Na}$ verdade, Hegel deve ser visto como um representante da tradição cameralista, sendo uma das evidências a sua preferência pelo uso da palavra staatökonomie. ${ }^{49} \mathrm{O}$ ponto de Kristofory é enfatizar Hegel como um «economizing philosopher» ${ }^{50}$ ou seja, todas as suas propostas econômicas devem ser vistas sob esse prisma, a saber, de sua filosofia geral.

Contudo, tanto Priddat quanto Ruda, conforme Kristofory, tomam Hegel por um economista (a despeito das distintas abordagens). Com isso, ambos perdem de vista um importante argumento que atinge a questão da plebe: «O papel histórico mundial do comércio ${ }^{51}$-no que Hegel seguiria Adam Smith. ${ }^{52}$ Ou seja, mais do que ter em vista propriamente a realização de um resto econômico mal resolvido nas sociedades modernas, a plebe é o veículo de eticização que o comércio promove nas sociedades, civilizando-as, instituindo a troca,

46 KRISTOFORY, T., Hegel's Emigrating Rabble and Export of Institutions of Civil Society, op. cit., p. 1.

47 Ibid., p. 3.

48 MARX, K., Manuscritos Econômico-Filosóficos, Boitempo: São Paulo, 2010, p. 124.

49 KRISTOFORY, T., Hegel's Emigrating Rabble and Export of Institutions of Civil Society, op. cit., p. 4. Sobre o assunto, ainda pouco estudado no Brasil, ver o paper apresentado no $41^{\circ}$ Encontro de Nacional de Economia por CUNHA, A. Johann Heinrich Gottlob von Justi (1717-1771) e o pensamento econômico cameralista. Disponível em https://www.anpec.org.br/encontro/2013/files_l/ i1-cc13586f1b74fb47d210954fb8b44aa5.pdf ; Acesso em 13/04/2018. Ver ainda sobre o cameralismo FEIJÓ, R. História do Pensamento Econômico, São Paulo, Atlas, 2007, pp. 62-64.

50 KRISTOFORY, T., Hegel's Emigrating Rabble and Export of Institutions of Civil Society, op. cit., p. 4.

51 Ibid., p. 5.

52 Ibid., p. 30. 
aumentando a produção. Nesse sentido, a plebe é resolvida: «e assim é como a categoria da plebe é imediatamente superada filosoficamente no interior do sistema de Hegel. A superação filosófica da categoria da plebe significa a transição à imediata categoria seguinte». ${ }^{53}$ Não está aqui em questão a pobreza propriamente dita, pois ela mesma não será superada, mas sim a plebe. A própria teoria econômica da época, segundo a análise de Kristofory, não teria resolvido a questão da pobreza, portanto seria ocioso exigir do próprio Hegel uma resposta.

Segundo Kristofory, o próximo movimento dos Estados Unidos no interior da dinâmica descrita por Hegel na Filosofia da história implicaria em guerra com a América Latina a fim de se escoar a plebe e promover nova colonização, tendo em vista a expansão das sociedades civis ao longo do globo. Kristofory ainda argumenta que o estudo de Hegel sobre a plebe se concentra em países que experimentaram movimentos migratórios e colonizadores, daí que «se a plebe emergiu com a economia em crescimento, é natural que fosse estudada no exemplo da Inglaterra, e não na Itália ou França». ${ }^{54}$ Por fim, Kristofory ainda menciona e critica um marxismo sub-reptício que daria o tom em algumas interpretações, como em Ruda e Chamley.

Tentarei mostrar a partir de agora quais os problemas que me parecem estar presentes em ambos os comentadores. Frank Ruda esforçar-se em reconstituir o estado da questão de modo amplo, e nisso residem vários de seus méritos. Um dos principais consiste em demonstrar os erros de avaliação de Avineri a respeito do tratamento que Hegel dispensou à questão. De maneira convincente, Ruda evidencia que Hegel esboçou várias respostas. Além disso, é importante ressaltar a menção e a abordagem pormenorizada do problema da plebe rica, o que foi um resultado novo das pesquisas. Até então, plebe e pobreza eram conceitos tanto mais indistintos quanto menos se fazia essa importante clivagem. Esse movimento de Ruda permitiu se enfocar corretamente os traços distintivos que realmente definem a plebe.

Não oferecerei aqui, propriamente, uma contestação direta, mas apenas vou sugerir de maneira oblíqua as insuficiências de Ruda. A melhor maneira de contrapor-se à sua visão é oferecer uma resposta alternativa à questão, o que não é plenamente exequível nesse espaço. A reconstrução filológica e histórica de Ruda vem acompanhada de um certo projeto filosófico que pensa Hegel a partir de Marx, e nisso vê a plebe pobre, a qual confere prioridade analítica e peso maior no interior de seu sistema, como uma espécie de proletariado intuído por Hegel. As consequências dessa ideia, se levadas a sério, conduziriam ao perecimento do modelo de Estado hegeliano. ${ }^{55}$ Para tanto, Ruda se compromete a

53 Ibid., p. 5.

54 Ibid., p. 17. Como veremos, essa é uma subestimação de Kristofory que redundará em um erro.

55 TIDRE, P., «Hegel e a Populaça (Pöbel)», Revista Eletrônica Estudos Hegelianos 16 (27), 2019, pp, 119-148, p. 144. 
completar Hegel. Como projeto filosófico, sem dúvida, é algo fascinante, embora seja possível francamente redarguir: precisa Hegel ser completado? Em termos filosóficos a resposta pode bem ser positiva -e os escritos de Ruda, por si mesmos, são de um profundo interesse nesse sentido-, no entanto as alternativas de se pensar a questão no interior do pensamento de Hegel deveriam antes se mostrar esgotadas -e não parece que nesse quesito Ruda tenha sido exitoso.

Minha objeção a Ruda se dá em dois passos. O primeiro é, digamos, histórico e filológico. Frequentemente Hegel elenca também correspondentes «empíricos» e históricos daquilo que ele entende por plebe. As citações são esparsas, todavia valem ser marcadas e desdobradas. Na Filosofia da história, Hegel faz menções reveladoras à plebe, de modo geral em contextos de ruína social, o que poderia, superficialmente, parecer corroborar a tese de Ruda. Uma de suas aparições se dá em uma menção ao contexto medieval e à solicitação das cidades italianas para que o Imperador Romano as «libertasse do domínio da plebe nas cidades [von der Pöbelherrschaft in den Städten] ou das violências generalizadas da nobreza». ${ }^{56}$ Outra menção se dá no contexto do Império Bizantino, de modo que a plebe é considerada como indomada, selvagem, portadora de um cristianismo que privilegiava os ritos exteriores sem atuar como princípio interior e estruturador da religião.$^{57}$ A plebe aqui é apresentada, de modo coerente com outras passagens, como um fenômeno das cidades - em que pese o baixo desenvolvimento urbano típico da Idade Média. Além disso, vê-se que o domínio dela é deletério. A passagem mais importante, porém, encontra-se na Filosofia do direito, quando Hegel identifica explicitamente a plebe aos lazzaroni em Nápoles. ${ }^{58}$ Até aqui poderíamos pensar que o traço comum dessas menções, em diferentes épocas históricas, se resume a populações urbanas, degradadas, pobres, mais ou menos tomadas como selvagens. O ponto essencial, porém, reside no fato de que Marx e Engels também mencionaram os lazzaroni. Eles o fizeram do seguinte modo: «em Nápoles os lazzaroni, aliados à monarquia, contra a burguesia. Em Paris, a maior luta histórica já travada. A burguesia, aliada aos lazzaroni, contra a classe trabalhadora». ${ }^{59} \mathrm{Ou}$ seja, Marx e Engels pensaram os lazzaroni como consumidos por um caráter claramente contrarrevolucionário. Em sua definição canônica do lumpemproletariado, no 18 de Brumário de Luís Bonaparte, Marx explicitamente, em sua enumeração classificatória, incorpora os

56 HEGEL, G. W. F., Filosofia da história, UNB, Brasília, 1995, p. 324; HEGEL, G. W. F., Vorlesungen über die Philosophie der Geschichte, Suhrkamp, Frankfurt am Main, 1986, p. 465.

57 HEGEL, G. W. F., Filosofia da História, op. cit., p. 287; HEGEL, G. W. F., Vorlesungen über die PhiIosophie der Geschichte, op. cit., p. 409.

58 HEGEL, G. W. F., A sociedade civil-burguesa, op. cit., § 244, p. 75; HEGEL, G. W. F., Grundlinien der Philosophie des Rechts, op. cit., pp. 389-390.

59 ENGELS, F.y MARX, K., Die Kontrerevolution in Berlin, en: Marx-Engels Werke, Dietz, Berlin, 1961, tomo VI, p. 10. 
lazzaroni a ela ${ }^{60}$ Bem pesado, tomar a plebe e o proletariado como duas formas de um mesmo fenômeno é forçado e indevido na medida em que nem conceitualmente nem «empiricamente» eles podem ser identificados. Ainda que nenhuma superposição funcione bem, o próprio Hegel (pelas menções acima), teria a plebe como algo mais próximo do lumpemproletariado. No lusco-fusco das sugestões teóricas de Hegel talvez fosse possível aproximar plebe e proletariado, contudo a ênfase aqui é que se faça valer os escritos históricos como uma espécie de «controle empírico» frente à imaginação teórica e à analogia. ${ }^{61}$

O segundo ponto consiste em criticar a leitura de Ruda das alternativas que podem ser consideradas como respostas ao problema da plebe. Em seu artigo A populaça ou: o fim do Estado hegeliano Ruda considera três leituras possíveis a partir do problema da plebe, isto é, da reconstrução aporética que podemos fazer dos $\S \S 243-248$. Por razões de espaço, considera-se aqui a terceira leitura, a qual Ruda assume como sua. Essa leitura propõe que

alguém poderia argumentar que uma pessoa qualquer poderia e deveria desenvolver a consequência do conceito de populaça que Hegel não desenvolveu, mas ao mesmo tempo deveriam ser enfatizadas essas consequências, embora elas demonstrem uma limitação interna do conceito de Estado, que Hegel apresenta, provam por fim um ponto hegeliano: a saber elas oferecem uma razão do porquê o Estado que Hegel apreende, em um certo ponto, irá perecer e decair, tal como todos os indivíduos, todo Estado individual tem uma vida que começa, expande-se e termina. A populaça poderia ser então tomada como sendo uma (e talvez não a única) explicação conceitual do porquê o apagamento do Estado hegeliano tem ou teve de ocorrer. ${ }^{62}$

A consequência da leitura de Ruda implica em pensar a indignação da plebe como uma forma de auto-respeito, um direito à existência: «a indignação da

60 MARX, K., O 18 de Brumário de Luís Bonaparte, Boitempo, São Paulo, 2011, p. 91.

61 Além dos escritos históricos e políticos, aludo aqui à Ciência da lógica, em especial quando Hegel, próximo ao final do livro, no capítulo «A ideia absoluta», procede à explicação da dialética. Em polêmica contra a contestação do movimento empreendida por Diógenes o Cão -o mero caminhar em oposição à objeção conceitual-, Hegel menciona tratar-se de uma «refutação plebeia» (pöbelhafte Widerlegung), isto é, tenazmente orientada pelo sensível e incapaz de alcançar níveis mais elevados do pensamento exigidos, por exemplo, para o tratamento de questões éticas. Ainda que esparsa, a investigação em torno da plebe em seu componente lógico plausivelmente leva à demonstração de que nela não há potencialidade normativa qualquer, mas antes uma afirmação do imediato. HEGEL, G. W. F., Ciência da lógica. A doutrina do conceito, Vozes, Petrópolis, 2018, p. 321; HEGEL, G. W. F., Wissenschaft der Logik II. Suhrkamp, Frankfurt am Main, 1986, p. 559.

62 RUDA, F., «A populaça ou: o fim do Estado hegeliano», op. cit., p. 9. 
populaça em sua dimensão latentemente universal indica, portanto, que o vínculo social já foi quebrado». ${ }^{63} \mathrm{Ou}$ seja, a emergência da plebe demonstra que o Estado já soçobra ${ }^{64}$. Contrapor esse ponto exigiria uma reconstrução mais detalhada do que se poderia oferecer aqui, todavia sinoticamente é possível, e mesmo aconselhável, separar de maneira mais radical o fenômeno da pobreza do fenômeno da mentalidade da plebe (a existência de uma plebe rica, cuja disposição psicossocial se manifesta na afluência, acaba por legitimar esse procedimento). Geoff Mann sintetizou a questão da seguinte forma:

Hegel não acredita que a pobreza pode ser eliminada ou curada. Ele acredita que a «mentalidade de plebe» pode ser subjugada, mesmo superada em um Estado que se torna ético, mas a pobreza não desaparecerá como uma consequência. «Remediar» é melhor entendido aqui como «tratar», isto é, gerir, cuidar [...] A questão da pobreza per se não é passível de uma cura. [...] Em resumo, a questão para Hegel é precisamente a mesma com a qual Robespierre se viu enredado em 1792: a possibilidade de uma pobreza honrada na ordem liberal. ${ }^{65}$

A tese geral de Geoff Mann é que a pobreza, como questão transhistórica, não é vista como um problema da mesma maneira que a plebe. Se a pobreza é necessária, a plebe não o é. Há dois argumentos subsidiários para embasar essa afirmação. O primeiro é o reconhecimento de que há diferenças evidentes nos processos de formação nacional. Basta se pensar no relato de Hegel acerca da Inglaterra no escrito sobre o Reformbill. ${ }^{66}$ A proporção de plebe na Inglaterra é muito diferente da Alemanha, de maneira que é possível inferir que o que se está em questão são formações nacionais mais ou menos bem

63 Ibid., p. 17.

$64 \bigcirc$ ○ 544 da Enciclopédia talvez pudesse ser visto como evidência suplementar a essa tese, na medida em que Hegel escreve sobre o povo em sua relação com o Estado nos seguintes termos: «Costuma-se chamar povo o agregado das pessoas privadas, mas, enquanto tal agregado, ele é o vulgo, não o povo [vulgus, populus]; e sob esse respeito é o único fim do Estado que um povo não chegue à existência, nem ao poder, nem à ação enquanto um tal agregado», HEGEL, G. W. F., Enciclopédia das ciências filosóficas em compêndio, Loyola, São Paulo, 1995, vol. 3, § 544, p. 315. Contudo, o contexto nesse trecho diz respeito à participação de pessoas privadas no Estado, sem a devida mediação. Não basta um Estado racional: é preciso que o próprio povo o seja também: «Para que tenha um sentido entrar na questão da participação das pessoas privadas nos assuntos universais, deve-se pressupor não o irracional, mas um povo já organizado», ibid., p. 315. Ou seja, esse tipo de participação atomizada dos indivíduos no Estado -o povo como agregado, portanto não através de estamentos- é ela própria resultado de falhas de socialização no que concerne a outros dispositivos estatais, como a Polizei. Não por acaso é precisamente a Inglaterra que é citada como a forma desenvolvida desse tipo de patologia.

65 MANN, G., In the long run we are all dead. Keynesianism, Political Economy, and Revolution, Verso, London/New York, 2017, p. 172.

66 HEGEL, G. W. F., Political Writings, Cambridge University Press, Cambridge, 2004. 
sucedidas, nas quais o êxito ou o malogro das instituições garante o aparecimento e dimensão da pobreza e da plebe - a Inglaterra é, nesse sentido, o exemplo a ser evitado, uma sociedade cujo componente privado se exacerbou e hipertrofiou a ponto de macular as demais instituições, por exemplo nos subornos generalizados. ${ }^{67}$

A segunda questão a ser ressaltada é sobre como entender o papel da plebe na economia argumentativa da Filosofia do direito. Esse ponto é fundamental. Isso porque a plebe é normalmente vista como um resultado necessário de todas as sociedades modernas, uma categoria que na ordem expositiva se faz sempre presente. Nesse caso, propõe-se aqui separar a ordem expositiva da ordem empírica. Para fazer esse trecho da argumentação mais transparente, vale realizar uma analogia com a noção de «demência» no terceiro volume da Enciclopédia:

Essa nossa apreensão da demência, como forma ou grau que surge necessariamente no desenvolvimento da alma, não deve ser entendida, naturalmente, como se por ela se afirmasse que cada espírito, cada alma, devesse passar por esse estado de demência extrema. Tal afirmação seria tão insensata quanto talvez a suposição de que, pelo fato de ser o crime considerado como um fenômeno necessário na Filosofia do direito, se deveria, por isso, fazer a perpetração de crime e uma necessidade inevitável para cada [indivíduo] singular. O crime e a demência são extremos que o espírito humano em geral deve superar no curso de seu desenvolvimento, porém que não aparecem em cada homem como extremos, mas somente na forma de limitações, de erros, de tolices e de falta não criminosa. Isso é o bastante, para justificar nossa consideração da demência como grau essencial do desenvolvimento da alma. ${ }^{68}$

No mesmo sentido é proposto pensar-se a plebe: é plausível pensa-la não como uma necessidade empírica de todas as sociedades, ainda que ela seja uma tendência inscrita em seu desenvolvimento. Ela é uma possibilidade extremada do processo de formação das sociedades modernas. Todo homem é sujeito a cometer crimes, mas nem todos os cometem, aliás, a maioria não o faz - toda sociedade é passível de ver nela surgir uma plebe numerosa, mas nem em todas isso ocorre. A hipótese aqui defendida é que sem diferenciar o registro «expositivo» do «empírico» a análise está, de antemão, comprometida. Uma parte das observações de Hegel a respeito da plebe se dá, precisamente, nesse nível empírico. Disso se segue que seja legítimo anotar que as críticas dirigidas a Hegel por seu tratamento não sistemático da plebe não são razoáveis. 
Valeria assinalar, antes, que «essas aparentes fraquezas poderiam, contudo, ser reavaliadas como pontos fortes: a postura de Hegel se distingue não por meio de teimosia doutrinária, mas sim por realismo e flexibilidade pragmática». ${ }^{69}$

Kristofory por sua vez acaba por cair, digamos, no erro oposto. A sua interpretação hiperliberal de Hegel, ideologicamente motivada, precisa dar peso a citações marginais, obliterar o sentido de afirmações essenciais e simplesmente esquecer certos problemas a fim de garantir uma interpretação apologética do capitalismo. Com isso, contudo, é preciso dizer que sua pesquisa é de qualidade, levanta autores e citações relevantes e ainda não completamente trabalhadas; a crítica aqui se dirige à interpretação sugerida, e não implica em diminuição da qualidade da pesquisa. A despeito da interpretação, a meu ver, ser muito problemática, seu levantamento é bastante adequado.

Dito isso, passemos à primeira questão, a saber, o peso dado ao papel do comércio. A principal evidência desse papel -que de fato existe, embora seja realmente duvidoso que caiba à plebe realiza-lo-é amparado basicamente em uma citação da Filosofia da história que correlaciona a Inglaterra ao comércio:

A existência material da Inglaterra baseia-se no comércio e na indústria, e os ingleses assumiram a grande tarefa de ser os missionários da civilização em todo o mundo, pois seu espírito comercial impulsiona-os a revistar todos os mares e todos os países, a ter ligações com os povos bárbaros, a despertar neles necessidades e atividades e, principalmente, a estabelecer, entre eles, as condições para o comércio: a abolição das violências e o respeito perante a propriedade e a hospitalidade. ${ }^{70}$

Há pelo menos dois problemas nessa démarche de Kristofory. Um ponto que é possível notar desde já diz respeito ao peso dado a esse argumento. Além dessa menção, há aquela do §246 da Filosofia do direito. Contudo, o comércio, ou a troca, é uma solução que precisa ser compreendida no interior de uma grande resolução que tem a colonização como etapa mais alta - e a colonização é um processo violento que resulta em sua autoabolição. ${ }^{71}$ Ademais, é preciso estabelecer corretamente o papel que os ingleses cumprem na compreensão de Hegel conforme seu enquadramento das nações. Sabe-se que não estão no patamar mais alto, não sendo comparáveis aos alemães. ${ }^{72} \mathrm{Em}$ resumo, há que se nuançar o peso dado ao papel civilizador do comércio, na

69 WASZEK, N., «Saint-Simonismus und Hegelianismus», en: WASZEK, N. (Ed.), Hegelianismus und Saint-Simonismus, Mentis Verlag, Paderborn, 2007, p. 23.

70 HEGEL, G. W. F., Filosofia da história, op. cit., p. 372; HEGEL, G. W. F., Vorlesungen über die Philosophie der Geschichte, op. cit., p. 538.

71 HEGEL, G. W. F., A sociedade civil-burguesa, op. cit., § 248, p. 79; HEGEL, G. W. F., Grundlinien der Philosophie des Rechts, op. cit., p. 393.

72 ROSENZWEIG, F., Hegel e o Estado, op. cit., p. 580. 
medida em que: i) além de não ter um papel na economia do texto hegeliano como Kristofory busca nos convencer, ii) é um movimento protagonizado por uma nação cujas principais referências de Hegel passam ao largo do enaltecimento, como o artigo sobre o Reformbill atesta.

Uma ideia realmente estranha e aparentemente despropositada é a noção de guerra tal como empregada por Kristofory. Ele argumenta em uma provável guerra de Estados Unidos contra a América Latina:

Bem, como mostramos antes, Hegel prevê que a plebe surgirá nos EUA em algum momento no futuro, e a consequência será que talvez lute contra a América do Sul. Eu deduzo que a guerra seria travada para o estabelecimento de colônias. A dedução adicional é que depois que as sociedades civis também surgirem, novas colônias serão estabelecidas em outros lugares, até que - em princípio- as instituições da sociedade civil estejam espalhadas por todo o mundo. Isso soa um belo final hegeliano. ${ }^{73}$

Essa ideia não parece ser razoável. Segundo a própria estrutura interna da $\mathrm{Fi}^{-}$ losofia do direito, o tema da guerra não aparece como derivado das dinâmicas das sociedades civis, mas sim ligado à particularidade dos próprios Estados, ao seu caráter de indivíduos históricos. Além disso, Kristofory parece pensar num caráter francamente civilizatório promovido pela guerra, na medida em que ela alastra e generaliza sociedades civis ao longo do mundo. Claudio Cesa lembra:

Se não me equivoco, o único reconhecimento explícito de uma função civilizadora da guerra se acha no lugar onde se fala da empresa de Alexandre Magno; em compensação, em relação às guerras dos romanos e dos germanos, Hegel não compartilha nem o entusiasmo de certos iluministas pela virtude e a tolerância pelas qualidades do povo romano, nem o de certos contemporâneos seus pela saúde física e moral dos povos germânicos; trata-se, em ambos os casos, de povos depredadores, incapazes inclusive de reelaborar autonomamente os valores da civilização com a qual entraram em contato. ${ }^{74}$

Ou seja, ainda que seja um argumento dado como «provável» por Kristofory, não parece ser possível pensa-lo como minimamente persuasivo. Talvez, inclusive, sirva para pensar como sua abordagem é problemática. O que o

73 KRISTOFORY, T., Hegel's Emigrating Rabble and Export of Institutions of Civil Society, op. cit., p. 5.

74 CESA, C., "Consideraciones sobre la teoría hegeliana de la guerra», en: COLL, G. A. (Ed.), Estudios sobre la 'Filosofia del derecho de Hegel, Madrid, Centro de Estudios Constitucionales, 1989, p. 335. 
argumento sugere é basicamente uma guerra colonialista. Denis Rosenfield lembra que o papel da guerra vai no exato contrário a esse delineado por Kristofory: «Hegel vê a guerra -à parte ser ela um dado real das sociedades do seu tempo e, de um modo mais geral, de toda a história- como um meio de evitar uma privatização excessiva da vida e de elevar a consciência que um povo tem de si». ${ }^{75} \mathrm{Ou}$ seja, ao invés de ser uma ampliação das dinâmicas privadas inscritas nas sociedades civis, ela ocupa no pensamento de Hegel outro papel, ligado precisamente à universalidade.

Hegel, a altura do adendo ao $§ 248$, sustenta que o fim das colônias é bom para as metrópoles, embora não ofereça razões claras disso. Kristofory, correta e unilateralmente, argumenta: «eu deduzo que a razão é o crescimento do volume de troca internacional, o qual ajuda os ricos a crescer e mitigar alguma parte do problema da pobreza» ${ }^{76}$. O que se revela aqui é um certo tipo de enquadramento da questão: embora Kristofory esteja correto, não parece que o único argumento de Hegel seja primariamente «funcional»-há, na verdade, um argumento ético, ligado à liberdade e autonomia, e não apenas ao incremento do comércio; essa dimensão ética precisaria ser enfatizada -a qual, no fundo, não parece importar muito a Kristofory.

Kristofory aponta ainda, corretamente, que as plebes antigas e modernas têm diferenças, relacionadas ao fato de que as sociedades antigas não possuíam uma sociedade civil propriamente dita. Porém, problemas assemelhados concernem a ambas as plebes. Esse acordo, todavia, não elide o que me parecem dois erros de tratamento fundamentais. $\mathrm{O}$ primeiro diz respeito à sua sustentação de que foi a plebe que conduziu a colonização antiga. Isso parece um erro, na medida em que foram os sentimentos de liberdade e dignidade que conduziram os homens a uma busca por novos caminhos:

Todavia, uma parte da classe pobre não queria se submeter ao estado de miséria, pois todos se sentiam cidadãos livres, e a única solução que lhes restou foi, portanto, a colonização. Em outra terra, aqueles que passavam necessidade em sua pátria poderiam ocupar terras e sobreviver como cidadãos livres, por meio da agricultura. ${ }^{77}$

Kristofory confunde aqui plebe e pobreza: de fato foram os pobres que realizaram a colonização; supor esse sentimento de liberdade nessa camada da população tomada como plebe é já extrapolar em muito o conceito de plebe delineado pelo próprio Hegel, na medida em que ele se caracteriza pela ausência desse tipo de valor.

75 ROSENFIELD, D., Política e Liberdade em Hegel, São Paulo, Ática, 1995, p. 271.

76 KRISTOFORY, T., Hegel's Emigrating Rabble and Export of Institutions of Civil Society, op. cit., p. 7.

77 HEGEL, G. W. F., Filosofia da História, op. cit., p. 197. 
O outro aspecto decisivo reside na sua interpretação na razão pela qual consistiu no caráter «paliativo» dessa colonização. Ele sustenta: «a presença de tiranos e a ausência de respeito pelo sujeito foram a base da queda da Grécia Antiga». ${ }^{78}$ Não se trata disso. Ao contrário, a posição de Hegel sobre os tiranos é avaliada - de modo matizado- positivamente, como um passo necessário à realização da liberdade. ${ }^{79}$

Por fim, o último problema diz respeito à ideia segundo a qual os locais que devem ser estudados sobre a plebe são aqueles que chegaram a ter colônias. Essa é uma abordagem restritiva, problemática e mesmo errada. Segundo Kristofory:

A Inglaterra é a nação mais economicamente desenvolvida da era de Hegel. Se a plebe emergiu com a economia em crescimento, é natural que ela fosse estudada no exemplo da Inglaterra, em vez da Itália ou da França. A nação italiana não tinha sequer o seu estado que poderia ter estabelecido a estrutura da sociedade civil. Como veremos mais adiante, os impactos da plebe não podem ser estudados em um país que não tem colônias, já que a meta da plebe para Hegel é exportar as instituições da sociedade civil. Isso era impossível na Itália, sem estado nacional e colônias. ${ }^{80}$

Isso leva Kristofory a interpretar o $§ 248$ em termos estritamente nacionais, e não propriamente estendendo seu alcance ao conjunto da dinâmica das sociedades modernas:

Assim, a conclusão deste parágrafo consiste em nosso argumento de que a plebe inglesa não permanece na Inglaterra e migra para os EUA, onde ela deixa de existir. A Inglaterra continua a manter relações ainda mais positivas com os EUA, particularmente as econômicas, após a Independência deste último. Portanto, a plebe não é uma contradição inerente que constitui o ponto de partida da linha original de pensamento de Hegel, como é o caso de Ruda. Há uma superação da plebe nos EUA. Pela lógica do argumento de Hegel, a plebe surgirá também nos EUA após o surgimento da sociedade civil ali. Veremos mais adiante que essa aparente complicação servirá ao papel histórico mundial de Hegel. Mas primeiro vamos esclarecer quem é o que pertence a esta plebe para Hegel, porque existem alguns grupos surpreendentes entre eles. ${ }^{81}$

78 KRISTOFORY, T., Hegel's Emigrating Rabble and Export of Institutions of Civil Society, op. cit., p. 34.

79 HEGEL, G. W. F., Filosofia da História, op. cit., p. 197; HEGEL, G. W. F., Enciclopédia das ciências filosóficas em compêndio, § 435, op. cit., pp. 205-206.

80 KRISTOFORY, T., Hegel's Emigrating Rabble and Export of Institutions of Civil Society, op. cit., p. 17.

81 Ibid, p. 24. 
Nisso residem dois problemas. O primeiro deles diz respeito à renitência da plebe na Inglaterra. A fim de se negar isso precisaria se evitar todo o conteúdo do artigo sobre o Reformbill. Segundo Kristofory, o problema é exportado aos Estados Unidos e resolvido, mas a leitura do artigo atesta que não: a plebe permanece como um nó terrível no ordenamento econômico da Inglaterra - com amplas consequências para a estrutura política. A consequência a ser retirada é que a resolução não se dá apenas por mecanismos econômicos estritos; do contrário, realmente a Inglaterra seria paradigmática. Ou seja, aceitar o argumento de Kristofory significa subtrair o próprio Hegel. O segundo ponto diz respeito ao estudo da plebe estar restringido à Inglaterra. Que ela seja o caso principal e exemplar não há dúvidas; mas a interdição é duvidosa. Ainda que essa perspectiva pareça rigorosa conforme a apresentação categorial da Filosofia do direito, a plebe reaparece em outros ordenamentos, como por exemplo na Itália, conforme menciona a Filosofia da história. Que não tenha se tornado um problema tão amplo ou que não tenha sido ensejo para a promoção do comércio e colonização como ocorrido em relação à Inglaterra, não desmente sua existência, em si mesma problemática. Em resumo, a plebe existe e pode ser estudada em qualquer lugar no qual ela se faça presente, de modo que a interdição não faz sentido.

As interpretações contemporâneas da plebe ofereceram muito mais elementos para se compreender o lugar dela no edifício hegeliano -seja como um dano estrutural, seja como a mostra definitiva de sua solidez. Contudo, como resultado, sugerimos que, embora avancem bastante na compreensão da plebe, as interpretações de Ruda e Kristofory acabam por obscurecer uma resposta que o próprio Hegel poderia oferecer ao problema se ele fosse interrogado de forma imanente, isto é, se se buscasse a coerência de sua posição nas variadas menções que fez da plebe -nem apologeta do capitalismo, nem uma filosofia cuja existência já é sintoma dos estertores da ordem liberal. Nesse sentido, é preciso observar as diferenças entre os conceitos de plebe e pobreza e, sobretudo no que diz respeito a Ruda, estabelecer os níveis do discurso de Hegel. ${ }^{82}$ A maneira e modo de se entender a extensão das afirmações de Hegel -se válidas ao conjunto de todas as sociedades modernas ou se circunscritas a apenas algumas dessas sociedades nacionais; se necessárias ou tendenciais - definem de maneira crucial a interpretação adotada. Sem determinar o estatuto do discurso de Hegel e cotejá-lo com as menções esparsas nos textos históricos e políticos se perde o critério empírico e o resultado é uma analogia com o proletariado- quando, melhor, seria comparar a plebe ao lumpemproletariado. Por outro lado, a tentativa de Kristofory de subsumir

82 A inspiração desse tipo de procedimento pode ser rastreada em LEBRUN, G., A Paciência do Conceito, UNESP, São Paulo, 2006. Contudo, como é evidente, não há semelhança na maneira como Lebrun entende o discurso de Hegel e como se tentou desenvolvê-lo aqui. 
Hegel a uma espécie de arqui-neoliberal é bastante duvidosa por conferir a trechos menores um peso decisivo.

O resultado de nossa investigação tenciona mostrar que a interrogação imanente a Hegel sobre o problema da plebe permite que, recolhendo suas variadas menções, possamos fazer um quadro mais completo e equilibrado que resulta em uma teoria da modernidade - aqui apenas aludida- que, comparativamente, estabelece critérios de processos de formação social mais ou menos exitosos. É esse tipo de procedimento, aliás, que ajuda a conferir maior inteligibilidade às constantes referências à Inglaterra, França e Alemanha. A plebe não é da ordem da necessidade incontornável - do mesmo modo que a demência ou o crime não são para o indivíduo, ainda que a apresentação científica exija o trato com essas categorias- e, portanto, a sua existência expressa sobretudo processos disfuncionais específicos, ainda que potencialmente presentes em toda as dinâmicas sociais modernas. Nesse sentido, o Hegel que resulta desse texto é o pensador que buscou se manter na tênue e difícil integridade tensa dos tempos modernos que, de resto, ainda é nosso tempo. ${ }^{83}$ 


\section{Bibliografia}

ADORNO, T. W., Sociologia, Ática, São Paulo, 1994.

—, Três estudos sobre Hegel, UNESP, São Paulo, 2013.

AVINERI, S., Hegel's theory of the modern state, Cambridge, New York, 1972.

BUCHWALTER, A. (Ed.), Hegel and Capitalism, Suny Press, New York, 2015.

GESA, C., «Consideraciones sobre la teoría hegeliana de la guerra», en: COLL, G. A. (Ed.), Estudios sobre la 'Filosofia del derecho' de Hegel, Madrid, Centro de Estudios Constitucionales, 1989.

DRI, R., «A filosofia do Estado ético. A concepção hegeliana do Estado», en: BORON, A. (Ed.), Filosofia politica moderna. De Hobbes a Marx, CLACSO, San Pablo, 2006.

EICHENBERGER, H. V., «A plebe segundo os intérpretes de Hegel», en: CORREIA, A. DEBONA, V. y TASSINARI, R. (Eds.), Hegel e Schopenhauer, São Paulo: ANPOF, 2017.

—, Pobreza e Plebe em Hegel. 2018. 195. Tese (Doutorado em Filosofia), Universidade Federal do Paraná, Curitiba, 2018.

FEIJÓ, R., História do Pensamento Econômico, Atlas, São Paulo, 2007.

FERGUSON, A., «Do Luxo», en: PIMENTA, Pedro Paulo (Ed.), O Iluminismo Escocês, Alameda, São Paulo, 2011.

HARVEY, D., A Produção Capitalista do Espaço, Annablume, São Paulo, 2005.

HEGEL, G. W. F., Grundlinien der Philosophie des Rechts, Suhrkamp, Frankfurt am Main, 1986.

——, A sociedade civil-burguesa, IFCH/UNICAMP, Campinas, 1996.

—_ Ciência da Lógica - A Doutrina do Conceito, Vozes, Petrópolis, 2018.

—, Die Philosophie des Rechts. Vorlesung von 1821/22, Suhrkamp, Frankfurt am Main, 2005.

—_, Enciclopédia das Ciências Filosóficas em Compêndio, vol. 3, Loyola, São Paulo, 1995.

—_, Filosofia do Direito, Loyola/UNISINOS, São Paulo/São Leopoldo, 2010.

—, Political Writings, Cambridge University Press, Cambridge, 2004.

—., Wissenschaft der Logik II, Suhrkamp, Frankfurt am Main, 1986.

KRISTOFORY, T., Hegel's Emigrating Rabble and Export of Institutions of Civil Society, October 2015. Disponível em: https://pt.scribd.com/document/306659733/Hegels-Par-243248-GPR; Acesso em 28/01/2018

LEBRUN, G., A Paciência do Conceito, UNESP, São Paulo, 2006.

LEUVEN, S. H., «The Problem of Poverty and the Rabble: Against the Neo-Marxist Critique of Hegel», en: ARNDT, A. et al. Hegel Fahrbuch-2014: Hegel gegen Hegel I, de Gruyter, Berlin/München/Boston, 2014.

LUKÁC.S, G., O Jovem Hegel e os problemas da sociedade capitalista, Boitempo, São Paulo, 2018.

MANN, G., In the long run we are all dead - Keynesianism, Political Economy, and Revolution, Verso, London/New York, 2017.

MARCUSE, H., «Zum Begriff der Negation in der Dialektik», en: Ideen zu einer kritischen Theorie der Gesellschaft, Suhrkamp, Frankfurt am Main, 1970.

MARX, K y ENGELS, F., Marx-Engels Werke, Dietz, Berlin, 1961. 
MARX, K., Manuscritos Econômico-Filosóficos, Boitempo, São Paulo, 2010.

——, O 18 de Brumário de Luís Bonaparte, Boitempo, São Paulo, 2011.

ROSENFIELD, D., Politica e Liberdade em Hegel, São Paulo, Ática, 1995.

ROSEnZWEIG, F., Hegel e o Estado, Perspectiva, São Paulo, Perspectiva, 2008

— - Hegel und der Staat, Bd. II, Oldenbourg, München und Berlin, 1920.

RUDA, F., «A populaça ou: o fim do Estado hegeliano», Revista Eletrônica Estudos Hegelianos 16 (28), 2019, 1-22.

—- Hegel's Rabble. A investigation into Hegel's Philosophy of Right, Continuum, London, 2011.

—, Hegels Pöbel. Eine Untersuchung der Grundlinien der Philosophie des Rechts, Konstanz University Press, Konstanz, 2011.

TIDRE, P., «Hegel e a Populaça», Revista Eletrônica Estudos Hegelianos 16 (27), 2019, pp. 119-148.

WASZEK, N., «Saint-Simonismus und Hegelianismus», en: WASZEK, N. (Ed.), Hegelianismus und Saint-Simonismus, Mentis Verlag, Paderborn, 2007.

—_, «O mendigo escocês de Hegel», Revista Eletrônica Estudos Hegelianos, 15 (26), 2018, pp. 235-241.

WEIL, E., Hegel e o Estado, É Realizações, São Paulo, 2011.

ŽIŽEK, S., Menos que nada: Hegel e a sombra do materialismo dialético, Boitempo, São Paulo, 2013. 